\title{
Geleneksel Kalkınma Yardımı Anlayışına Eleştirel Bir Bakış
}

DOI: $10.26466 /$ opus.690706

$*$

\author{
Esat İpek* - Erdal Tanas Karagöl ${ }^{* *}$ \\ * Araş. Gör., Ankara Yıldırım Beyazıt Üni./Sosyal Bilimler Ens, Sosyal Politika ABD, \\ Ankara/Türkiye \\ E-Posta: esatipek@hotmail.com \\ ORCID: $0000-0003-0440-9690$ \\ ** Prof. Dr., Ankara Yıldırım Beyazıt Üniversitesi/Siyasal Bilgiler Fakültesi, Ankara/Türkiye \\ E-Posta: erdalkaragol@hotmail.com \\ ORCID: 0000-0003-0803-4064 \\ Öz
}

Kalkınma yardımları en basit haliyle; kalkınmış ülkelerin, kalkınmamış ülkeleri, transfer ettikleri kaynaklar yoluyla desteklemeleridir. Ancak bahse konu kalkınmış ve kalkınmamış karşıtlı̆̆ının dayanak noktası olan Batı merkezci bakış açısı, ülkeler arısında başta siyasi, ekonomik ve askeri olmak üzere bir güç dengesizliği ortaya çıkarmaktadır. Bu da donör ve faydalanıcı ülkeler arasında bir çeşit patronaj ve hiyerarşiye sebep olmaktadır. Dünya'nın farklı bölgelerinde en fazla askeri gücü olan ülkelerin, ayn zamanda en önde gelen donör ülkeler olması, bu durumun sahadaki somut tezahürüdür.

Bahse konu siyasi, ekonomik ve askeri güç dengesizlĭgi, donör ve faydalanıcı ülkeler arasındaki patronaj ilişkisinin de kaynağını teşkil etmektedir. Donör ülkeler bu ilişki sayesinde, kendi çıkarların güttükleri nüfuz alanları oluşturmaktadırlar. Faydalanıc ülkelerin, donör ülkelerle yaşayacağı en ufak bir gerilim bile bu ülkelerin siyasi ve ekonomik açıdan ciddi problemler yaşamasına sebep olabilmektedir. Donör ülkelerin sahip oldukları hiyerarşik üstünlük, bu ülkelerin benimsemiş oldukları anlayış ve politikaların, faydalanıcı ülkeler tarafindan koşulsuz bir şekilde kabullenilmesini zaruri kılmaktadır. Faydalanıcı ülkelerin talep ve önceliklerinin ikinci planda kalmasina neden olan bu durum, teorik temelleri Rostow'un Aşamalı Kalknma Modeline dayanan geleneksel kalkınma yardımı anlayışının ortaya çıkardı̆̆̆ en büyük problemdir.

Bu çalışmada, bahse konu geleneksel kalkınma yardımı anlayışının ortaya çıkışı ve tarihsel gelişim/dönüşüm süreci açıklanmakta ve bu anlayışı benimseyen donör ülkelerin sundukları kalkınma yardımları bağlamında sahip oldukları strateji ve politikalar incelenmektedir. Ayrıca, bahse konu donör ülkelerin, kalkınma yardımı faaliyeti yürüttükleri ülkelerle olan ilişkileri de bu çalı̧̧mada tartışlmaktadır. Söz konusu tartı̧̧maların odağındaki donörler arasından seçilen bazı ülke örnekleri de bahse konu tartışmaların sahaya somut bir şekil nasıl yansıdı̆̆ın göstermesi bakımından önem arz etmektedir. Örnek ülkeler belirlenirken, 1950'lerden sonra ortaya çıkan geleneksel kalkınma yardımları anlayışın benimseyen ilk ülkeler olmasına ve tarihsel olarak ortaya çıkan yapısal ve kurumsal dönüşümleri göstermelerine özen gösterilmiştir.

Anahtar Kelimeler: kalkınma, Rostow modeli, batı merkezci anlayış, kalkınma yardımları 


\title{
Traditional Development Assistance Understanding A Critical Overview
}

\begin{abstract}
Development assistance, theoretically and in its simplest definition, is the support provided to underdeveloped countries by developed countries through the transfer of resources. However, the Western centered perspective (the West and the rest) based on this developed and underdeveloped contrast creates a power imbalance between countries in terms of particularly political, economic and military areas. And this leads to a sort of patronage and hierarchy between the donor and beneficiary countries. The fact that the countries with the most military power in various regions of the world are the leading donor countries at the same time is a concrete manifestation of this situation.

The political, economic and military imbalance in question also constitutes the source of the patronage relationship between the donor and beneficiary countries. Thanks to this relationship, the donor countries builds their zones of influence in which they pursue their own interests. Even the smallest tension occurring between the donor and beneficiary countries may cause the beneficiary countries experience serious political and economic problems. The hierarchical superiority of the donor countries makes it compulsory for the beneficiary countries to unconditionally accept the approach and policies adopted by the donor countries. This situation which causes the demands and priorities of the donor countries to be of secondary importance is the biggest problem resulting from the conventional understanding of development assistance.

In this study, the appearance of the conventional understanding of development assistance in question and its historical development/transformation process are explained and the strategies and policies adopted by the donor countries with this type of development assistance understanding are examined in the contest of the development assistance they provide. Furthermore, the relationship which the donor countries establish with the countries they provide development assistance is also discussed within the scope of the study. Some sample countries chosen among the donors which are the subject of the controversy regarding the issue are also important in terms of demonstrating the way in which the controversy in question is actually reflected on the field. In choosing the sample countries, it was aimed to select the countries which first adopted the conventional understanding of development assistance that appeared in the late 1950's and which represent the structural and institutional transformation in terms of historical development.
\end{abstract}

Keywords: development, Rostow model, western centrist understanding, development aids 


\section{Giriş}

Modern anlamdaki kalkınma yardımlarının ortaya çıkışı 1948-1951 yılları arasında uygulanan Marshall Yardım Programı'na dayanmaktadır. Bu plan, İkinci Dünya Savaşı dolayısıyla harap olan Avrupa devletlerinin yeniden kalkındırılmaları amacıyla hazırlanmış ve bugünkü anlamda uygulanan ilk kalkınma yardımı uygulaması olarak tarihe geçmiştir. Bu planın devamı niteliğinde olan Truman Doktrini ise komünizmin yayılmasının önüne geçmek ve Avrupa devletlerinin Savaş öncesindeki nüfuz ve güçlerini yeniden kazanmaları amacıyla ortaya çıkmıştır. Truman Doktrini sayesinde kalkınma yardımları alanına ABD haricinde birçok Batı Avrupa ülkesi donör olarak dahil olmuştur.

Eski sömürgeleriyle kesilen bağlarını yeniden tesis etmek isteyen Batı Avrupa ülkeleri, kalkınma yardımları aracılığıyla, bu ilişkiyi süreklilik arz eden bir bağımlılık ilişkisine dönüştürmüşlerdir. Bu da geleneksek kalkınma yardımı anlayışını ortaya çıkarmıştır. Teorik temelleri Rostow'un Beş Aşamalı Kalkınma Modeline dayandıran bu model, Avrupalı devletlere, yardım sundukları eski sömürgeleri karşısında yeniden hiyerarşik bir üstünlük sağlamiştır (Gökgöz, 2015, s.3).

1950'lerden sonra uluslararası kuruluşların dünya sahnesindeki yerlerini almaları, kalkınma yardımları alanında da bazı değişikliklerin yaşanmasını beraberinde getirmiştir. Yardımlarının bir kısmını bu kuruluşlar üzerinden sunmaya başlayan ülkeler sayesinde uluslararası kuruluşlar da kalkınma yardımları alanında donör olarak yer almaya başlamışlardır. Bu noktada geleneksel kalkınma yardımları anlayışı kısmi bir değişikliğe uğramış olsa da donör ülkelerin bu alana dair bakış açıları üzerinde kayda değer bir değişiklik meydana getirmemiştir. Eskiden olduğu gibi donör ülkelerin ulusal çıkarları, yardımların sunumundaki birinci öncelik olmaya devam etmiştir (McMichael, 2012, s.61-63).

Bu muhafazakarlığın en önemli sebebi ise uluslararası kuruluşların aldıkları kararların, geleneksel kalkınma yardımı anlayışını benimseyen donör ülkeler tarafından şekillendirilmesidir. Temsiliyet noktasında dominant konumda olan bahse konu ülkeler, uluslararası kuruluşların aldıkları kararları, kendi ulusal çıkarlarının zarar görmeyeceği şekilde yönlendirme kabiliyetine 
sahiptirler (Lancester, 2007, s.38). Bu durumun, kalkınma yardımları alanında ve diğer bütün uluslararası meselelerde, günümüzde de benzer şekilde devam ettiğini söylemek yanlış olmayacaktır.

1950'lerden sonra ortaya çıan modernist kalkınma paradigması da kalkınma yardımları alanın iki temel aktörü olan donörler ve faydalanıcılar arasındaki var olan hiyerarşik durumu daha da pekiştirmiştir. Özellikle Batı Avrupa ülkeleri üzerinden şekillendirilen bu kavram, "Batı ve diğerleri" ayr1mını somut bir şekilde ortaya koymuştur. Kalkınma konusunda Avrupa'yı mutlak doğru ve rehber konumuna getiren bu ayrım, kalkınma kavramının odağını Avrupa'dan; Latin Amerika'ya, Asya'ya, Afrika'ya ve Orta Doğu'ya kaydırmıştır. Bu bölgelerdeki pek çok ülkenin kendini yönetemez durumda olduğu ve kaynaklarını işleyecek kapasitelerinin olmadığı söylemi, kaynakların Batı'ya taşınmasının meşru gerekçesi haline gelmiştir. Bu durum, bahse konu bölgelerde yer alan ülkeler ile Batı Avrupa arasında, yeniden bir bağımllık tesis etmiştir (Wallerstein, 2006).

Kalkınma yardımlarının teorik olarak temel amacl; gelişmiş ülkelerden aktarılan kaynak, bilgi, tecrübe ve imkanlar sayesinde gelişmemiş ve gelişmekte olan ülkelerin kalkınma çabalarına destek olmaktır. Ancak yukarıda da anlatılan gerekçeler dolayısıyla bu argüman sadece retorikten ibaret hale gelmektedir. Günümüzde de donör ülkelerin ulusal çıarlarının birinci öncelik olarak kabul edildiği kalkınma yardımlarının, teorik amacını ne derece gerçekleştirebildiği, bu alandaki en büyük tartışma konularından birisidir. $\mathrm{Bu}$ çalışma bahse konu çelişkinin tarihsel olarak analizini ve bazı seçilmiş ülke örnekleri kapsamında somut olarak ortaya konulmasını hedeflemektedir. Örnek olarak seçilen ülkeler belirlenirken, 1950 'lerden sonra ortaya çıkan geleneksel kalkınma yardımları anlayışını benimseyen ilk ülkeler olmasına ve tarihsel sürecin nasıl işlediğine dair örnek gösterilebilecek yapısal ve kurumsal dönüşümlerin de değerlendirilebilmesini sağlayacak ülkeler olmasına özen gösterilmiştir.

\section{Geleneksel Kalkınma Anlayışı}

Bugünkü bilinen haliyle kalkınma yardımları, İkinci Dünya Savaşı yüzünden nerdeyse tamamen yıkılma noktasına gelmiş Batı Avrupa ülkelerinin ve ekonomilerinin, yeniden canlandırılması için ABD tarafından başlatılan Marshall Yardım Programı ile literatüre girmiştir. Bu programın temel amacı, Avrupa 
ekonomilerine yeniden işlerlik kazandırmak ve küresel ticareti tekrar canlandırmaktır. ABD tarafından sunulan desteklerle toparlanan ve küresel ticaretteki yerlerini yeniden almaya başlayan Avrupa ekonomileri, yine ABD'den çıkan bir doktrin ile kalkınma yardımları alanında faydalanıcı olarak değil de donör olarak yer almaya başlamışlardır (McMichael, 2012, s.61-63).

1947 yılında, dönemin ABD başkan Harry Truman, ABD ve Avrupa için küresel boyutta bir tehlike olarak gördüğü komünizmin önüne geçmek için ve Avrupa ülkelerinin özellikle savaş öncesi dönemde nüfuz sahibi oldukları bölgelerde yeniden var olabilmeleri için kalkınma yardımlarını bir araç olarak işaret etmiştir. Bu kapsamda $\mathrm{ABD}$, komünizm tehdidi altında olduğunu düşündüğü ülkelere askeri ve mali destek sunarak, küresel boyutta bir ittifak zinciri kurmayı hedeflemiştir (Mahmat, 2008, s.15). Bu adım, Soğuk Savaş döneminde ortaya çıkan, Doğu ve Batı bloklarının da oluşmasına ön ayak olmuştur.

1950'lere gelindiğinde ABD haricinde, başta Birleşik Krallık, Fransa ve Hollanda olmak üzere birçok Batı Avrupa ülkesi, kalkınma yardımları alanında donör olarak faaliyet göstermeye başlamışlardır. Özellikle eski sömürgeleriyle kesintiye uğrayan ticari ilişkilerini yeniden tesis etmek ve süreklilik arz eden bir bağımlılık ilişkisi kurmak stratejisiyle hareket eden Batı Avrupa ülkeleri, kalkınma yardımları literatüründe geleneksel kalkınma anlayışı olarak bilinen yaklaşımın ortaya çıkmasını sağlamışlardır (Pettinger, 2017).

Geleneksel kalkınma modeli teorik olarak Rostow'un Aşamalı Kalkınma Modeline dayanmaktadır. Bu modele göre gelişmemiş ülkelerin kalkınması uzun bir süreçtir ve bu süreç beş aşamadan oluşmaktadır. Bu aşamalar; ekonominin tarımsal faaliyetlerden ibaret olduğu geleneksel toplum aşaması; altyapı yatırımlarının başladığı ve sosyal ve kültürel değerlerin değişime uğradığ1 kalkışa geçiş aşaması; sanayileşmenin başladığı ve tasarruflarla imalat sektörünün desteklendiği kalkış aşaması; teknolojik gelişmelerle birlikte ağır imalat sanayiinden, yüksek teknolojili üretime geçildiği olgunlaşma aşaması; refah toplumunun gerçekleştiği, ülkenin merkez ülke konumuna geldiği, etrafındaki ülkelere üstünlük kurmaya başladığı ve bu ülkeleri mali ve askeri olarak desteklemeye başladığı kitlesel tüketim aşamasıdır (Alagöz, 2004, s.26).

Rostow'a göre kitlesel tüketim aşaması, kalkınma sürecinin son aşamasıdır ve Batı Avrupa devletleri artık bu noktadadırlar. Burada üzerinde durulması gereken nokta, gelişim sürecini tamamlayan ülkeler ile gelişmemiş 
ve/veya gelişmekte olan ülkeler arasında ortaya çıkan hiyerarşik bakış açısıdır. İşte bu bakış açısı geleneksel kalkınma yardımı anlayışının teorik temellerini oluşturmaktadır. Pek çok farklı görüş tarafından eleştirilen bu bakış açısı, 1950'lerden sonra, uluslararası kuruluşların dünya sahnesine çımalarıyla ve kalkınma yardımları alanına dahil olmalarıyla kısmi bir değişikliğe uğramıştır (Alagöz, 2004, s.2-6).

ABD, Hollanda ve Fransa gibi ülkelerin başını çektiği Batılı ülkeler, kalkınma yardımı faaliyetlerini, 1950'lerden sonra; Dünya Bankası, IMF ve Birleşmiş Milletler gibi uluslararası kuruluşların da etkisiyle, yeniden şekillendirmişler ve bahse konu faaliyetlerinin bir kısmını bu kuruluşlar aracılığıyla yürütmeye başlamışlardır (McMichael, 2012, s.61-63). Ancak bahse konu yeniden yapılanmanın ülkelerin sahip oldukları anlayış üzerinde kayda değer bir değişiklik meydana getirdiğini söylemek doğru olmayacaktır. Zira, söz konusu uluslararası kuruluşların yapılanmalarından kaynaklanan durumun doğal bir sonucu olarak, bu kuruluşların benimsedikleri anlayış da geleneksel kalkınma anlayışının devamı niteliğindedir. Yani asıl öncelik, donörlerin stratejik çıkarları ve uluslararası hedefleridir (Lancester, 2007, s.41).

1950'lerden sonra ortaya çıkan uluslararası kuruluşların şekillendirdiği modernleşme kavramı, teorik açıdan ve pratik olarak, Batı ve diğerleri (West and the rest) arasında hiyerarşik bir güç ilişkisi kurmuştur (Six, 2009). Bu ilişki Avrupa ülkelerini, sadece tarihi belirleyen aktörler yapmamış, aynı zamanda kalkınma ve kalkınmanın aşamaları konusunda da büyük bir tecrübeyle donatmıştır. Bu tecrübe, dünyanın geri kalanı için kalkınma konusunda, mutlak doğru kabul edilen, bir tür model halini almıştır. Batı merkezci kalkınma anlayışıyla, sömürgeciliğin birleşimi, iki önemli sonuç üretmiştir. Bunlardan birincisi, kalkınmanın odağının, Avrupa'nın kendisinden diğer ülkelere doğru kaymış olması ikincisi ise coğrafi odaklanmanın Batı'dan; Latin Amerika, Afrika, Asya ve Orta Doğu'ya kaymasıdır (Six, 2009, s.1121). Yani, kalkınma uygulamalarının hedefi artık başkaları olmuştur.

Sömürülen milletlerin, kendilerini yönetme ve kaynaklarını işletme kapasitesinden yoksun olduğu ön kabulü, sömürgeci uygulamaların ve milletlerin sahip olduğu zenginlikleri Batıya taşımanın, meşrulaştırıcı söylemi haline gelmiştir. Eski sömürge konumunda olan ülkelerde güç kazanan ırka dayalı ideolojiler ve İkinci Dünya Savaşı'ndan sonra hız kazanan bağımsızlaşma hareketleri, bahse konu meşrulaştırıcı söylemi geçersiz kılmıştır. Ancak, yeni 
söylemlerin ortaya çıkarak, aynı işlevi icra etmeleri noktasında hiç vakit kaybedilmemiştir. Sömürgecilik sonrası dönemde, "medeni-barbar" karşıtllğının yerini; ekonomik durgunluğa karşı, üretkenliği ve geleneğe karşı, modernliği savunan "kalkınmış-kalkınamamış" karşıtlığı almıştır (Ziai, 2007, s.64-65).

\section{Donör Ülkelerin Benimsedikleri Stratejiler}

Kalkınma yardımlarının geleneksel yapısı, 1980'lerdeki borç krizi dolayısıyla, bir tür çıkmaza girmiştir. Yaşanan kriz, yol ve baraj inşası gibi büyük altyapı yatırımlarını finanse etme modelinden vazgeçilmesine sebep olmuştur. Siyasi reformları desteklemek, kalkınma yardımlarının ana ekseni haline gelmiştir. Az gelişmiş ve gelişmekte olan ülkelerde, yeterli bilgi sahibi olmadan, yardım ve yatırım yapmak yerine, sürdürülebilir nitelikte olan, siyasi reformlara yatırım yapmanın daha etkili olacağı bu dönüşümün temel gerekçesidir. DB ve IMF gibi uluslararası kuruluşların, proje temelli destekler yerine, Yapısal Uyum Programları (SAP) adı altında, yeni araçları kullanmaya başlamaları da bu dönüşümün motivasyonlarındandır (Dollar ve Svensson, 2000, s.901).

Donör konumunda olan her ülkenin kendine has bir yardım programı bulunmaktadır. Diğer taraftan; DB ve IMF tarafindan belirlenen politik eksen, bütün donörlerin yardım programlarını yönlendirip, yeniden şekillendirmektedir (Woods, 2008). Yardım faydalanıcısı ülkelerin, donörler ve uluslararası kuruluşlar tarafından belirlenen politikaları takip etmesi ve yönetim yapılarını bu politikalar doğrultusunda dönüştürmeleri, uluslararası kuruluşlar tarafından yürütülen SAP uygulamalarını, kalkınma yardımları alanında öne çıarmaktadır (Dreher vd., 2011, s.1955).

Yardım faydalanıcısı ülkelerden hayata geçirilmesi istenilen dönüşümler, ağırlıklı olarak ekonomik alanlara yöneliktir. SAP’lerin ilan edilen amacı; yardım alan ülkelerin ekonomilerini, küresel serbest piyasa rekabetine hazırlamaktır. Diğer taraftan, borç ve petrol krizlerinin yıprattı̆̆, kapalı ekonomiye sahip ülkelerin devlet varlıkları, özelleştirme yoluyla satılmaktadır. SAP’ler, küresel sermaye için bu ülkeleri, yatırım açısından güvenilir hale getirmektedir (McMichael, 2012, s.61-63).

IMF tarafından hazırlanan stand-by anlaşmaları da bu kapsamda değerlendirilebilir. SAP'ler ve stand-by anlaşmaları; DB ve IMF tarafından önceden belirlenen koşulların, yardım talebinde bulunanlar tarafından, peşinen kabul 
edilmesi şartıyla işleyen, merkezi bir yapıya dayanmaktadır. Dolayısıyla, yardım faydalanıcısı ülkelerin süreçten dışlandığı eleştirilerine cevap olarak, Yoksulluğu Azaltma Strateji Belgeleri (PRSP) ortaya çıkmıştır. 1990'lı yıllarda SAP'lerin yerini, PRSP'ler almıştır. Ancak, temelde yine donörlerin çıkarları ön planda tutulduğu için PRSP'lerin de başarılı olduğunu söylemek pek mümkün değildir (Craig ve Porter, 2003, s.55).

2000'lere gelindiğinde, Bin Yıl Kalkınma Hedefleri (BKH) BM tarafından, kalkınma yardımı alanında olan bütün aktörlerin, ulaşması gereken hedefler olarak ilan edilmiştir. 2014 yılı sonu itibarıyla, başta Türkiye olmak üzere, birçok ülke belirlenen hedeflerin bazılarına ulaştıysa da bazıları için halen kat edilmesi gereken uzun mesafeler bulunmaktadır. BKH için belirlenen süre, 2000-2015 yılları arasını kapsayan dönemdir. 2015 yılında ise yine BM, Sürdürülebilir Kalkınma Hedefleri (SKH) adıyla, 2030 yılına kadar takip edilmesi öngörülen, yeni hedefler belirlemiştir. Kalkınma yardımı alanındaki aktörlerin hepsi için bağlayıcı özelliği olan bahse konu hedeflerin; yoksulluğu azaltma, çevre duyarlılığı, yönetişim, toplumsal cinsiyet eşitsizliği ve kalkınma yardımları gibi hususları gündeme getirmesi, geçmişteki kalkınma yaklaşımıyla karşılaştırıldığında, büyük bir ilerleme olarak değerlendirilebilir (Easterly, 2007).

Diğer taraftan, bütün bu dönüşüm çabalarına rağmen, geleneksel kalkınma anlayışını benimsemiş olan donörler, kalkınma yardımlarını her şart ve koşulda kendi stratejilerine göre hayata geçirme kabiliyeti ve imkanına sahiptirler. Fransa, Hollanda, Birleşik Krallık ve ABD gibi donör ülkeler açısından, eski sömürgeler ve stratejik müttefikler, kalkınma yardımına ihtiyaçları olup olmadığına bakılmaksızın, yardım faydalanıcısı birer ülke olarak, bahse konu donör ülkeler nezdinde öncelikli yerlerini korumuşlardır (Alesina ve Weder, 2002, s.1130).

Geleneksel kalkınma yardımı anlayışına sahip donörlerin kalkınma yardımı stratejileri açısından benimsedikleri bir diğer ortak özellik de proje ve programların; merkezi olarak planlanıp, yerelde uygulanmaya çalışılmasıdır. Kalkınma yardımlarında merkezi planlamanın; tecrübelerden faydalanmak, mükerrerlikleri önlemek ve uzmanlık bilgisini kullanmak gibi olumlu etkileri olsa da yereldeki yardıma muhtaç insanların hayatlarına doğrudan etki etmesi hususu, pratiğe oldukça zor geçmektedir. Merkezi planlamanın, genelleştirilmiş örnekler üzerinden, donör ülkenin kendine göre en iyi ve ideal 
yöntemi tasarlayarak hayata geçirmeye çalışması ve sunulan yardımların yereldeki faydalanıcılar açısından uygun olup olmadığı değerlendirmesinin sadece eldeki veri ve istatistiki bilgiye dayanılarak yapılması, son derece sınırlı ve yetersiz kalmaktadır (Moyo, 2010, s.22-25).

Sınırlı bilgiye ve istatistiğe dayanarak, merkezi yapılar tarafından uygulamaya konulan projelerin başarısızlığı için İtalya'nın, Afrika'daki kalkınma yardımı projelerinden birinde uzman olarak görev yapan, Ernesto Sirolli'nin (1999) teknik işbirliği proje tecrübesi yerinde bir örnek olarak değerlendirilebilir. Bahse konu örnek, geleneksel donörlerin kalkınma yardımlarına yönelik yaklaşımları ve merkezi planlamanın ortaya çıkardığı yerelden kopukluğun sonuçlarını göstermesi açısından önemli görülmektedir (Sirolli, 1999 akt. Arslan, 2015, s.55-56).

Sirolli 1970'lerde, bir yardım çalışanı olarak, Afrika'da, Zambezi Nehri'nin kıyısında yaşayan yerli halka, domates yetiştiriciliği konusunda eğitim vermek için görevlendirilmiştir. Proje kapsamında; domates yetiştiriciliği için uygun tarım arazilerinin seçilmesi, domates yetiştiriciliği bağlamında yerli halka eğitim verilmesi ve bir pilot uygulama gerçekleştirilmesi gibi aşamalar yer almaktadır. Yerel halktan gelen itirazlara rağmen, uzmanlar tarafından, toprak kalitesi göz önünde bulundurularak, Zambezi Nehri kıyısında bir bölge pilot uygulama yapılması için uygun görülmüştür.

Modern tarım teknolojileri ve yöntemleri sayesinde, pilot uygulamadan kısa sürede olum bir sonuç alınmış ve nehir kıyısında bol ürün veren domates tarlaları oluşmaya başlamıştır. Projede görevli batılı uzmanlar, yerel halkın asırlardır neden nehir kıyısındaki bu verimli topraklarda tarım yapmadıklarını, onların tarım konusundaki bilgisizliklerine bağlamışlardır.

Proje süresince, batılı mesai kültürüne alışık olmayan bölge halkı, eğitim ve çalışmalara katılmayı aksatmaya başlayınca, onları teşvik etmek adına işe gelmeleri için halka hediyeler dağıtılmıştır. Ancak, domateslerin hasat zamanında, işçilere verilecek hediyeler tükenince, tarlalarda çalıştıracak kimse bulunamamıştır. Diğer taraftan kalkınma uzmanları, mevsimsel geçişler dolayısıyla, pilot uygulama kapsamında yapılan tarım faaliyetlerini bozan nehrin ve çokça emek vererek olgunlaştırdıkları domateslerin, su aygırları tarafından bir gecede nasıl talan edildiğine şahit olarak, neden bu bölgede tarım yapılmadığını -geç de olsa- kavramışlardır.

$\mathrm{Bu}$ örnekten de anlaşılacağı üzere geleneksel donörler, kendi çıkarları doğrultusunda geliştirdikleri yardım programlarını, faydalanıı ülkelerdeki 
yerel bilgi ve tecrübeye başvurmadan, kendi ön kabulleriyle uygulama ve sonuç alma eğilimindedirler. Ayrıca bu örnek, domates üretiminin İtalya'daki sos sektörü açısından önemi hasebiyle, geleneksel kalkınma anlayışını benimseyen donörlerin, kalkınma yardımı uygulamaları ile ulusal çıkarları arasında, nasıl bir bağ kurduklarını somut bir şekilde ortaya koyması açısından da önemlidir (Arslan, 2015).

Benzer tecrübeler, kalkınma yardımlarına en çok ihtiyacı olan "En Az Gelişmiş Ülkeler" de (EAGÜ) uygulanan pek çok kalkınma yardımı projesinin, yardımların etkisizliğini ortaya çıkarması açısından önemli bir işlev görmektedir. Zira 1980'lerden bu yana, sunulan onca kalkınma yardımına rağmen, 1994 yılında Botsvana; 2007 yılında Cape Verde; 2011 yılında Maldivler ve 2014 yılında Samoa haricinde hiçbir ülke, EAGÜ kategorisinden çıkamamıştır (UNDESA, 2015). BKH gibi uluslararası kabul görmüş kalkınma yardımı stratejileri, açık bir şekilde donör ülkeleri yoksulluğu azaltmak için daha fazla kaynak aktarmaya yönlendirmiş olsa da kalkınma yardımlarının etkisizliği, uluslararası kalkınma yardımlarının en temel problemlerinden ve gündem maddelerinden biri olmaya devam etmektedir (ECI, 2013).

Kalkınma yardımlarının etkinliğini arttırabilmek için OECD-DAC'ın liderliğinde özelikle 2000'li yıllarda pek çok çalışma yapılmıştır. 2002 yılında hayata geçirilen, Kalkınmanın Finansmanı için Monterrey Konsensüsü; 2005 yılında yayınlanan, Yardımların Etkinliği için Paris Bildirisi; 2008 yılında organize edilen, Eylem için Akra Gündemi ve 2011 yılında düzenlenen, Etkili Kalkınma İşbirliği için Busan Ortaklığı bu çalışmalardan bazılarıdır. Yapılan çalışmalar genellikle; yardımların kalkınmadaki rolüne, kalkınma programlarına yönelik yerel sahiplenmeyi arttrmaya, donör faaliyetlerinin ortak hedefler doğrultusunda uyumlulaştırılmasına, yardımlar sunulurken ortaya ç1kan maliyetleri düşürmeye ve sonuç odaklı ve karşılıklı hesap verilebilirliğe dayalı yönetim modellerinin oluşturmasına odaklanmıştır (OECD, 2011).

2005'deki Paris Bildirisinden sonra donörler, yardımların etkinliğini göz önünde bulundurarak, belirlenen ilkelere tam manasıyla uyacaklarını taahhüt etmişlerdir. Illkelere riayet etme notasında taahhütler verildikten sonra; ikinci adım, 2010 yılı için ölçülebilecek hedeflerin oluşturulmasıdır. Bu kapsamda 13 hedef belirlenmiş, ancak 2010 yılına gelindiğinde bunlardan sadece bir tanesi gerçekleştirilebilmiştir. Sunulacak teknik işbirliği yardımlarının yüzde 50'sinin, faydalanıcı ülkelerin kalkınma stratejileriyle uyumlu ve koordineli programlar olacağına dair hedef, karşılanabilen tek hedef olmuştur. 
Bahse konu diğer toplantı ve çalışmalarda da kayda değer manada bir ilerleme kaydedilememiştir (OECD, 2011).

Geleneksel donörlerin kalkınma yardımı politikaları uzun süre; Batı Avrupa'nın yeniden inşası, Japonya, Almanya, Tayvan ve Güney Kore gibi başarılı uygulama örneklerinden ilhamla, modern kalkınma yaklaşımına dayalı, merkez ülkelerde planlanmış ve emredici nitelikteki yapısını korumuştur (Alesina ve Dollar, 2000, s.41-44). Özellikle Batı Avrupalı geleneksel donörler, kendi kalkınma tecrübelerini, gelişmekte olan ülkelere transfer etmeye çalışarak, kalkınma aşamalarını çok detaylı ve başarılı bir şekilde pazarlarken; tarihi sömürgecilik miraslarını ve gözettikleri çıkarlarını her daim gizlemeyi başarmışlardır. Bu yaklaşım, kalkınma yardımlarının, insani saiklerle yapılmasının önündeki, en önemli engel olmuştur.

1980'li yıllardan sonra başlayan reform çabalarının, etkili olamamasının en önemli gerekçesi de bahse konu anlayıştır. Diğer taraftan, geleneksel kalkınma yardımları anlayışına yöneltilen eleştiriler, hiçbir zaman bu kapsamda sunulan yardımların değersiz olduğunu iddia etmemiştir. Eleştirilerin asıl odağı; harcanan kaynaklar, ileri sürülen söylemler ve ortaya konan çabalara rağmen, elde edilen sonuçların istenilen düzeyde olmamasıdır (Dollar ve Svensson, 2000, s.910).

\section{Donör Faydalanıcı İlişkileri}

Soğuk Savaş'ın sona ermesiyle birlikte; ekonomi, güvenlik, kalkınma ve uluslararası ilişkiler gibi birçok başlıkta, mevcut paradigmalar değişikliğe uğramıştır. Küreselleşmenin ve yeni küresel oyuncuların ortaya çıkması bu değişikliklerin en temel nedenlerindendir. Ancak her şeye rağmen; uluslararası ilişkiler, finansal ve askeri güce dayalı olarak şekillenmeye devam etmiştir. Kalkınma yardımlarındaki sömürgeci-sömürge; gelişmiş-gelişmemiş; zengin-yoksul; kentli-kırsal; medeni-ilkel ve modern-geri kalmış gibi karşıtlıkların çoğu bahse konu finansal ve askeri güç dengesine işaret etmektedir (Wallerstein, 2006).

Bu güç dengesi zamanla donörler ile yardım faydalanıcıları arasında bir çeşit patronaj ve hiyerarşi oluşturmuştur. ABD, Hollanda, Birleşik Krallık ve Fransa gibi geleneksel kalkınma anlayışını benimsemiş donörlerin, dünya genelindeki baskın askeri, ekonomik ve kültürel varlıkları, tarihsel olarak yardım yapan ve yardım alan ülkeler arasında, hiyerarşik biçimde kurulmuş 
olan güç dengesinin somut göstergesidir. Avrupa Birliği gibi birçok güçlü ülkenin bir araya gelmesiyle oluşmuş; ekonomik ve siyasi bir birliktelikte bile diğer üye ülkeler; kalkınma yardımlarından tutun da savunma, enerji ve ticaret gibi konularda, iki baskın ekonomik güç olan, Almanya ve Fransa'ya göre pozisyon almaktadırlar (Six, 2009, s.1110).

Dünyanın farklı ülke ve coğrafyalarında en çok askeri varllğı bulunan ülkeler, aynı zamanda en önde gelen donörler arasında yer almaktadırlar. ABD, Birleşik Krallık ve Fransa'nın askeri varlıkları, yardım sundukları ülkeler ile kendileri arasında, bir patronaj ilişkisinin ortaya çıkmasına yol açmaktadır. Özellikle Soğuk Savaş döneminde, ABD tarafından yapılan yardımlar ile aynı dönemde, ABD'nin rakibi olan Sovyetler Birliği tarafından yapılan yardımların askeri niteliği ve askeri üs bulundurma önceliği, bu hususu öne çıkmaktadır (Ehrenfeld, 2004).

Askeri varlığın, dünya genelinde yaygınlaşmış ekonomik güç olma durumunu beraberinde getirdiği düşünülmektedir. Küresel ekonomik güç dengesinin, askeri güç dengesiyle aynı doğrultuda olup olmadığına bakmak için uluslararası finansal akışların, ithalat ve ihracatın nereden nereye yapıldığı ve sermayenin toplandığı merkezler göz önünde bulundurulduğunda, kast edilen paralellik açıç̧a görülmektedir. ABD, küresel finansal akışları yöneten baskın güç olarak öne çımaktadır. Bu ülkenin sahip olduğu; küresel markalar, teknolojik üstünlükler sayesinde küresel sermayenin önemli bir bölümünü kontrol etmesi ve uluslararası kuruluşlardaki güçlü temsiliyeti, ABD'nin küresel piyasalardaki gücünü pekiştirmektedir (Mawdsley, 2014, s.51-53).

Dolayısıyla, yardım faydalanıcısı bir ülke için donör ülkelerle yaşayabileceği en ufak bir ekonomik ve/veya siyasi sorun, faydalanıcı ülkenin küresel piyasalardan kaynak, mal, hizmet, yardım veya finansman bulma imkanı açısından büyük problemlere yol açabilecektir. Donör ülkelerin baskın güç olma durumu, bu ülkeler tarafından hazırlanmış olan kalkınma reçetelerinin, herhangi bir dirençle karşılaşmadan, dünyanın pek çok yerinde uygulanmasına imkan tanımaktadır. Böylece, bahse konu donörler tarafından sunulan yard1mın, hedef ülkenin ihtiyaç ve öncelikleriyle ilişkisi, doğrudan ikinci plana atılmaktadır (Clay vd., 2009, s.26).

Yukarıda da değinildiği üzere, uluslararası ihracat ve ithalatta, geleneksel kalkınma anlayışını benimseyen donörlerin baskın konumu öne çıkmaktadır. 
Bu noktada, bahse konu donörlerin sundukları kalkınma yardımlarını, küresel ekonomideki baskın konumlarını daha da güçlendirecek şekilde yönettiklerini söylemek çok da yanlış olmayacaktır. Bazı donörlerin sundukları yardımın bir kısmını, kendi ürettikleri mallarının satın alımında kullanılmasını ön şart olarak ileri sürmeleri, bunun en güzel göstergesidir (Ehrenfeld, 2004).

Özellikle geleneksel kalkınma yardımı anlayışını benimsemiş olan bazı donörler tarafından, sunulan kalkınma yardımlarının kapsamlı ve uzun süreli proje ve programlar olması dolayısıyla, yönetimin uzun süre boyunca tek bir elde toplanması sayesinde, idari maliyetlerde tasarrufa sebep olacağı varsayımı ileri sürülmektedir. Bahse konu program ve proje türlerinin yönetim standartlarının yüksek olması, sayıları az da olsa yönetici, danışman ve teknik uzman gibi personellere ve diğer kalemlere yönelik yapılan harcamaları arttırmaktadır. Dolayısıyla, uzun vadeli strateji ve hedeflere dayalı programların, sunulan yardımlar içerisindeki idari maliyetleri düşürdüğü varsayımı, pratikte gerçeği yansıtmamaktadır (Easterly ve Pfutze, 2008, s.33).

OECD-DAC'a üye olan bütün donörler tarafından sunulan resmi kalkınma yardımı (RKY) miktarı, 2017 yılında 165 milyar 9 milyon Dolar olarak gerçekleşmiştir. Aynı yıl gerçekleşen Programlanabilir Ülke Yardımları (PÜY) miktarı ise 56 milyar 841 milyon Dolar olup, toplam RKY'nin yaklaşık yüzde 34'ü kadardır. Bu veri, geleneksel kalkınma anlayışını benimseyen OECD-DAC üyesi donörler tarafından sunulan kalkınma yardımlarının yarıdan fazlasının yardım alan ülkeler yerine, donörlerin idari harcamalarına gittiğini ve bu miktarın kendi ülkelerinde kaldığını göstermekte. Zira PÜY, ülkelerin sundukları yardımların, faydalanıc ülkelere ulaşan kısmını ifade etmektedir (OECD, 2020).

Donör ülkelerin verdiği taahhütlerin gerçekleşme durumu ve az gelişmiş ve gelişmekte olan ülkelerin kalkınma için ihtiyaç duyduğu kaynak miktarı dikkate alındığında, sunulan yardım miktarının yetersiz ve alınan sonuçların tatmin edici olmadığı ortaya çıkmaktadır. Bu noktada RKY tutarından, PÜY rakamları aracılığıyla, yardım faydalanıcısı ülkelere ulaşmayan yardım tutarı çıkarıldığında, faydalanıı ülkelerdeki faaliyetler için aktarılan kaynakların yetersizliği daha da net anlaşılmaktadır (Kharas ve Fengler, 2010, s.3-8).

Yardımların Etkinliği Üzerine Paris Bildirisi ve Eylem için Akra Gündemi'ne göre donör ülkelerin yardımlarını; sahiplenme, uyumluluk, sonuç odaklılık, harmonizasyon, karşıllıklı hesap verebilirlik ve kapsayıcı ortaklık ilkeleri çerçevesinde yapmaları gerekmektedir (OECD, 2011). Bu ilkeler, 
uzun yıllar süresince yürütülen kalkınma yardımı tecrübelerine dayanılarak belirlenmiştir. Yardımların etkililiği hususunun yanı sıra, bahse konu ilkelerin belirlenmesinin arkasındaki bir diğer motivasyon da kalkınma yardımları alanında sonradan donör sıfatını kazanan ve yükselen donör olarak anılan ülkelerin, geleneksel kalkınma anlayışını benimseyen, geleneksel donörlerin karşısına rakip olarak ortaya çıkmış olmalarıdır. Ancak, geleneksel donörlerin PÜY/RKY oranları göz önünde bulundurulduğunda, kendileri tarafından belirlenen kalkınma yardımı ilkelerinin, yine kendileri tarafından dikkate alınmadığı sonucu ortaya çıkmaktadır (Alesina ve Weder, 2002, s.1130).

Sonuç olarak, geleneksel donör konumunda olan ülkelerin, sundukları kalkınma yardımlarının; bahse konu ülkelerin ulusal çıkarları ve askeri ve ekonomik ilişkileri ile bağlantılı olduğu anlaşılmaktadır. Geleneksel donörler, uluslararası kabul görmüş ilkeleri kendileri ortaya koymuş ve söylem düzeyinde bu ilkelere uymaya hevesli olsalar da kendi çıarlarına hizmet etmediği sürece, onlar tarafından belirlenmiş bu ilkeler, sadece retorik düzeyinde kalmaktadır.

Bütün bu anlatılanlar doğrultusunda, geleneksel donör konumunda olan ülkelerin, yardım faydalanıcısı konumunda olan ülkelerle arasındaki ilişkinin, başta da ifade edildiği gibi hiyerarşik bir yapıda olduğu açıkça görülmektedir. Bu hiyerarşik yapı, sunulan yardımların nasıl hayata geçirileceği konusunda da doğrudan etkilidir. Özellikle geleneksel donörler, az gelişmiş ve gelişmekte olan ülkelerde yardım uygulamalarını nasıl hayata geçirecekleri hususunda, bazı ortak özelliklere sahiptirler. Bu özellikler; faydalanıcı ülkenin seçimi noktasında ihtiyaçtan ziyade stratejik hareket edilmesi, sunulan yardımların azımsanamayacak oranda bağlı yardım niteliğinde olması, idari ve benzeri nitelikte olan harcamaların sunulan yardımların önemli bir bölümünü teşkil etmesi ve karşılıklı kazan kazan ilkesi göz önünde bulundurulmadan yardımların ikili ticaretin geliştirilmesi için kullanılması şeklindedir.

\section{Seçilmiş Ülke Örnekleri}

Bu bölümde; başta ABD olmak üzere geleneksel kalkınma anlayışını benimsemiş olan bazı ülkelerin kalkınma yardımları bağlamında sahip oldukları tecrübe, benimsedikleri strateji ve faydalanıcı ülkelerle aralarında tesis ettikleri ilişkiler ülke örnekleri üzerinden açıklanmaya çalışılacaktır. Bu sayede, 
yukarıda yapılan tartışmaların daha somut ve anlaşılır bir şekilde incelenmesi mümkün olacaktır diye düşünülmektedir. Ülkeler seçilirken, 1950'lerden sonra ortaya çıkan geleneksel kalkınma yardımları anlayışını benimseyen ilk ülkeler olmasına ve tarihsel sürecin nasıl işlediğine dair örnek gösterilebilecek yapısal ve kurumsal dönüşümlerin de değerlendirilebilmesini sağlayacak ülkeler olmasına özen gösterilmiştir.

\section{Amerika Birleşik Devletleri}

1947-1950 yılları arasında, ABD tarafından hayata geçirilen Marshall Planı, modern anlamdaki ilk kalkınma yardımı uygulamasıdır. ABD'de 1951 yılında yürürlüğe giren Ortak Güvenlik Yasası dolayısıyla ve yardımların yönetimi amacıyla Ortak Güvenlik Ajansı kurulmuştur. Sonrasında ise Uluslararası İşbirliği İdaresi, Ortak Güvenlik Ajansı'nın yerine görev yapmaya başlamıştır. (Lancester, 2007, 63-80). 1959 yılında ise Amerikalılar Arası Kalkınma Bankası (IDB) kurulmuş ve ABD'deki tarım fazlası üretimin az gelişmiş ve gelişmekte olan ülkelere gıda yardımı olarak gönderilmesini öngören Gıda Yardımları Programı hayata geçirilmiştir. Bu program halen Geleceği Besle adı altında, bazı küçük değişikler yapılarak, ancak aynı amaca hizmet edecek şekilde devam ettirilmektedir (USAID, 2020a).

1961 yılında, ABD'nin sunduğu kalkınma yardımları organizasyonel olarak yeniden yapılandırılmış ve Dışişleri Bakanlığı'na bağlı bir birim olarak ABD Uluslararası Kalkınma Ajansı (USAID) kurulmuştur. ABD kalkınma yardımlarının üç ana ayağını oluşturan; Kalkınma Yardımları Programı ve Gıda Yardımları Programı, USAID tarafından; Güvenlik Desteği Yardımları Programı ise Dışişleri Bakanlığı'nın kendisi tarafından yönetilmeye başlanmıştır. Dünya Bankası ve diğer bölgesel kalkınma bankalarına aktarılan yardımların yönetilmesi görevi ise Hazine Bakanlığı'na verilmiştir (USAID, 2020b).

İki taraflı yardımlar, 1960'ların ortalarında siyaseten sorgulanmaya başlanmış ve ABD'yi çok taraflı yardımlara yöneltmiştir. Çok taraflı yardımların, toplam yardımlar içerisindeki payı, 1967'de yüzde 5 seviyesindeyken, 1975 yılında yüzde 30 seviyesine yükselmiştir. 1980'lerin başında, serbest piyasa düşüncesinin bütün dünyada, Dünya Bankası vasıtasıyla yaygınlaştırılması 
ve Güney Amerika ülkelerindeki liberal hükümetlerin desteklenmesi gibi politik hamleler, siyasetin ve kamuoyunun yardımlara olan desteğini tekrar arttırmıştır (Lancester, 2007, s. 80-82).

1990'ların başında Sovyetler Birliği'nin dağılmasıyla, ABD dış yardımlarının odağı; demokrasi, insan hakları ve çevre gibi konulara kaymışken, yaklaşık 10 yıl sonra, 11 Eylül 2001 saldırılarıyla beraber, ABD Ulusal Güvenlik Stratejisi'nde yer alan, dünya genelinde terörü önleyici müdahale anlayışı, ABD'nin; Afganistan'a ve Irak'a müdahalesine gerekçe oluşturmuştur. Bu doğrultuda ABD tarafından sunulan resmi kalkınma yardımı miktarı 2000 yılındaki 10 milyar Dolarlık seviyeden, 2005 yılında 28 milyar Dolar seviyesine yükselmiştir. Bu dönemde, bahse konu ülkelere yönelik askeri müdahalelerin oluşturduğu olumsuz algının normalleştirilmesi adına, müdahale edilen ülkelere yönelik sunulan yardımların, asıl amacı dışında kullanılan bir araç haline geldiği değerlendirilmektedir (Mawdsley, 2014, s.60-62).

ABD için kalkınma yardımlarının temel amacl; diğer ülkeler üzerinde politik etki oluşturmak olduğu değerlendirilmektedir. Zira USAID tarafından bu amaç; Amerika'nın ekonomik ve ulusal çıkarları doğrultusunda sunulan destekler şeklinde açıkça ifade edilmektedir. Bu amaç doğrultusunda, sunulan yardımların iki temel stratejiyle şekillendirildiği gözlemlenmektedir. Bunlardan ilki; güvenlik temelli yaklaşım kapsamında, yardım faydalanıcısı ülkelerin hükümetlerine, doğrudan hibe ya da kredi sağlanması şeklindedir. İkincisi ise kalkınma temelli yaklaşım kapsamında, ikili ya da çok taraflı yardımlar vasıtasıyla, az gelişmiş ve gelişmekte olan ülke ekonomilerinin güçlendirilmesidir (USAID, 2020c).

ABD, 2011 yılından itibaren, Küresel Kalkınma Politika Belgesi doğrultusunda, verdiği kalkınma yardımları için ülke ve bölge stratejileri hazırlanmaya başlanmıştır. 64 ülke ve 2 bölge stratejisi hali hazırda USAID tarafından hazırlanmıştır (USAID, 2020c). Strateji dokümanları incelendiğinde, ülke ve bölgelere özgü öncelik alanlarını belirleme açısından faydalı oldukları düşünülse de bahse konu dokümanların hazırlanması sürecinde yerel aktörlerle birlikte hareket edilmediği için ortaya çkan önceliklerin ABD'nin mi yoksa faydalanıcı ülkenin mi olduğu hususu tartışmalıdır.

ABD'nin sunduğu kalkınma yardımlarının bölgesel dağılımı incelendiğinde, ilan edilen dış politika ile bağlantılı bir planlamanın yapıldığı açıça görülmektedir. 1960'lı yılların ortalarından itibaren, Soğuk Savaş'ın karşıt ta- 
rafı olan Sovyetler Birliği'nin etki alanındaki Orta Asya ve Güney Asya ülkelerine yönelik sunulan yardımlar azalırken, yeni müttefiklerin kazanılabileceği potansiyel bölgeler olan Afrika ve Orta Doğu ülkelerine sunulan yardımlarda bir artış olduğu görülmektedir. 2000'lerden itibaren ise yukarıda da bahsedildiği gibi Afganistan ve Irak'a sunulan yardımlar keskin bir şekilde artmıştır (Moyo, 2009, s.27-30).

\section{Hollanda}

Hollanda'nın 2013 yılında sunduğu toplam RKY miktarı 4,9 milyar Dolardır. Bunun 1,8 milyar Doları yani yüzde 36,7'si çok taraflı kalkınma yardımlarına ayrılmıştır. Yine 2016 yılında RKY/GSYH oranı ise yüzde 0,65 seviyesindedir. 2008-2016 yıllarını kapsayan dönemde, Hollanda'nın ikili resmi kalkınma yardımlarından en çok faydalanan ülkeler; Demokratik Kongo Cumhuriyeti, Mozambik, Etiyopya, Sudan ve Gana'dır. (AidFlows, 2020a). Bu ülkeler; Güney Afrika'nın ilk sömürgeci devleti olan Hollanda'nın eski sömürgeleri ve onların sınır komşusu olan bazı ülkelerdir.

17'nci yüzyıldan, 20'nci yüzyıla kadar deniz aşırı pek çok ülke üzerinde nüfuz sahibi olan Hollanda'nın, kalkınma yardımları alanındaki ilk faaliyetleri, 19'uncu yüzyılda, sömürgelerine; bayındırlık, sanayi ve tarım alanında uzman görevlendirilmesi şeklinde gerçekleşmiştir (Spitz vd., 2013, s.8). Kalkınma yardımlarını ilk ortaya çıktığı zamandan itibaren benimseyen Hollanda, 1949 yılında, OECD bünyesinde kurulan, Denizaşırı Topraklar Komitesi'nin ve 1960 yılında kurulan, Kalkınma Yardımları Grubu'nun (DAG) ilk üyeleri arasındadır (Fuihrer, 1996, s.6-8).

1960'larda Hollandalı şirketlerin baskılarıyla, Ekonomik İşler Bakanlığı, Hollanda'nın ticari faaliyet yürüttüğü ülkelerde, ticaret odaklı projeleri desteklemiştir (Hoebink, 1999, s.184). Bu destekler Hollanda'nın kalkınma yardımı alanında yaptı̆̆ ilk çalışmalardır. 1964 yılından itibaren ise kurumsallaşma açısından önemli adımlar atılmaya başlanmıştır. Aynı yıl, Dışişleri Bakanlığı bünyesinde, kalkınma yardımlardan sorumlu bir müsteşarlık tesis edilmiş ve bakanlık bünyesinde, Uluslararası İşbirliği Genel Müdürlüğü kurulmuştur (Fuhrer, 1996, s.10). 1973 yılında, kalkınma yardımı faaliyetlerinde Dışişleri Bakanlığı tek sorumlu kurum haline gelmiştir. Kalkınma yardımları bütçesi de Ekonomik İşler Bakanlığı'ndan, Dışişleri Bakanlığı'na devredilmiştir (Hoebink, 1999, s.186). 
1970'lerde az gelişmiş ve gelişmekte olan ülkelerde, yoksullukla mücadeleye yönelik faaliyetler yürütülmüş ve demokratikleşme hareketleri desteklenmiştir. Bahse konu dönemde, Hollandalı STK'lar, kalkınma yardımları bağlamında muhatap olunan ülkelerdeki STK'larla işbirliği yaparak, kalkınma yardımı faaliyetlerinde aktif olarak yer almışlardır. Bu dönemde Hollanda'nın kalkınma yardımı anlayışında ahlaki değerler ağır basmaya başlamıştır. 1980'lerde ise ekonomik çıkarlar yeniden gündemdeki ağırlı̆ı̆ın arttırmış ve yardım faaliyetleri açısından belirleyici olmuştur (Spitz vd., 2013, s.11-12).

Kalkınma yardımları alanında Hollanda'nın öncelikleri, hükümet tarafından, meclise sunulan "Kalkınma İşbirliği Politikası" başlıklı mektuplarla belirlenmektedir. Bu konuda meclise sunulan en güncel doküman olan 2014 tarihli mektupta, Hollanda'nın bu alandaki politikalarında değişiklik yapılması gerektiği belirtilmiş, ekonomik ve sosyal sektörlerden ziyade, faydalanıcı ülkelerin kendi ayakları üzerinde durabilmelerine yönelik politikaların geliştirilmesi ve özel sektörün bu hususta desteklenmesi gerektiği ifade edilmiştir. Hollanda'nın öncelikli alanları; demokrasi, hukukun üstünlüğü, gıda güvenliği, üreme sağlığı, cinsel sağlık ve su yönetimi olarak ifade edilmektedir. Tespit edilen her alan için hedefler ve yöntemler yine bu mektuplarla açıklanmaktadır (MFA of the Netherlands, 2020).

\section{Fransa}

Fransa da Hollanda'ya benzer şekilde kalkınma yardımları kapsamında sunduğu ikili yardımlarını genel olarak; Fildişi Sahili, Fas, Kongo, Tunus ve Senegal gibi eski sömürgelerine aktarmaktadır. 1998 yılında, eski Fransız sömürgeleri; Sahra Altı Afrika, Orta Doğu, Hindiçin ve Pasifik bölgeleri Fransa tarafından "Öncelikli Dayanışma Bölgeleri" olarak tanımlanmıştır. Fransa, Avrupa kıtasında bulunmayan, Fransa Denizaşırı Bölgeler Topluluğu'na sunduğu yardımları da resmi kalkınma yardımı olarak raporlamaktadır. Ancak bu bölgeler, uluslararası toplum tarafindan zaten Fransa toprağı olarak kabul edilmektedir (Donor Tracker, 2019).

Fransa'nın sunduğu kalkınma yardımlarının koordinasyonu için 1998 y1lında, Uluslararası İşbirliği ve Kalkınma Komitesi adında, bakanlıklar arası bir komite oluşturulmuştur. Başbakan başkanlığında toplanan komite; Dışiş- 
leri, Kalkınma, Ekonomi ve Maliye, Bütçe, Eğitim, Yükseköğretim ve Araştırma, İçişleri, Savunma, Çevre, Dış Ticaret ve Denizaşırı Fransa Toprakları Bakanları'nın katılımıyla toplanmaktadır. Komitenin sekretaryasını Dışişleri Bakanlığı'yla birlikte, Ekonomi ve Maliye Bakanlığı yürütmektedir (France Ministry of Europe and Foreign Affairs, 2019).

Kalkınma yardımlarının bürokratik düzeyde organizasyonundan Dışişleri Bakanlığı'na bağlı olan Küresel İşler, Kalkınma ve Ortaklıklar Genel Müdürlüğü sorumludur. Bu genel müdürlüğün görevleri; ekonomik ve kültürel diplomasi ve kalkınma politikaları şeklindedir. Sunulan kalkınma yardımlarının politika belgeleri de bu genel müdürlükçe hazırlanmaktadır. Ayrıca 2013 yılında, Kalkınma ve Uluslararası Dayanışma için Ulusal Konsey kurulmuştur. Başbakan başkanlığında toplanan konsey, kalkınma yardımı politikalarının belirlenmesi sürecine; özel sektörün, STK'ların, yerel idarelerin ve milletvekillerinin dahil olması amaciyla oluşturulmuştur (France Ministry of Europe and Foreign Affairs, 2019).

Fransa kalkınma yardımı faaliyet alanlarını; göç, gıda güvenliği, iklim değişikliği, sosyal hizmet, yabancı yatırımlar ve ticaret olarak belirlemiştir. Fransa, kalkınma yardımı sunduğu faydalanıcı ülkelerle, Ortaklık Çerçeve Anlaşmaları imzalamaktadır. Bahse konu anlaşmalar genellikle dört yıllık süreler için yapılmakta ve ülke programı niteliği taşımaktadır (France Ministry of Europe and Foreign Affairs, 2019). Sunulan ikili yardımların yaklaşık yüzde 80'i, ekseriyetle Fransa'nın eski sömürgesi olma niteliği taşıyan, bu ülkelere aktarılmaktadır (AidFlows, 2020b). Ortaklık Çerçeve Anlaşmaları kapsamında yürütülen teknik işbirliği projelerinin yürütücüsü konumunda olan Fransa Kalkınma Ajansı (AFD) 1998 yılında kurulmuştur. AFD'nin görev ve yetkileri, Para ve Maliye Kanunu'nda tanımlanmış olup, Dışişleri Bakanlığı ve Ekonomi ve Maliye Bakanlığı ile koordineli bir şekilde çalışmaktadır (Law Library of Congress, 2011, s.129).

Fransa ulusal bütçesi, parlamento tarafından, tematik programlar ve bunların alt programlarından oluşan misyonlar şeklinde hazırlanmaktadır. Bahse konu alt programlar arasında harcama noktasında belirli bir esneklik imkanı bulunmaktadır. Bu çerçevede, kalkınma yardımı misyonu farklı bakanlıklara tanımlanmış olan alt programlardan oluşmaktadır. Bunlar arasındaki en büyük üç program ise Dışişleri Bakanlığı'na tanımlanmış olan, Gelişmekte Olan Ülkelerle Dayanışma Programı; Ekonomi ve Maliye Bakanlığı'na tanımlan- 
mış olan, Kalkınma için Mali Yardım Programı ve Göç ve Entegrasyon Bakanlığı'na tanımlanmış olan, Eş Kalkınma ve Göç Programı'dır (Law Library of Congress, 2011, 129-130).

\section{Sonuç}

1950'lerden, 1980'lere kadar özellikle Batı Avrupalı donör ülkelerin ve ABD'nin nüfuz oluşturma amaciyla, kalkınma yardımlanı kapsamında hayata geçirdikleri büyük altyapı projeleri, bu tarihten sonra demokrasinin yaygınlaştırılması ve serbest piyasa ekonomisinin benimsenmesi gibi siyasi ve ekonomik reformlara dönüşmeye başlamıştır. Bu dönüşümün en önemli tetikleyicilerinden bir tanesi Dünya Bankası ve IMF gibi uluslararası kuruluşların hayata geçirdiği programlardır (Dollar ve Svensson, 2000, s.903).

Uluslararası kuruluşların hayata geçirdiği bahse konu programlar, faydalanıcı konumunda olan ülkelerin kalkınma yardımlarından yararlanabilmeleri için kabullenip, uygulamaya geçirmeleri gerekli olan ön şartlar haline gelmişlerdir. Bu ön şartların temel amacı ise faydalanıcı konumunda olan ülkelerin, küresel sermayenin yatırım yapabilmesi için güvenli hale getirilmesidir. Ekonomik saiklerin başat unsur haline geldiği bu durum, yardım faydalanıcı ülkelerin önceliklerini, ihtiyaçlarını ve taleplerini tamamen ikinci plana atmaktadır (McMichael, 2012, s.61-63).

1990'larda pek çok eleştirinin kaynağı olan bu durum, söz konusu programların yoksulluk sorunu üzerine eğilmesine sebep olmuştur. 2000'li yılların başından itibaren ise birçok farklı konuda uzun vadeli hedeflerin belirlendiği Bin Yıl Kalkınma Hedefleri (BKH) gibi strateji belgeleri ortaya çıkmaya başlamıştır. 2000-2015 yıllarını kapsayan BKH'nin devamı niteliğinde olan ve 2015-2030 yılların kapsayan Sürdürülebilir Kalkınma Hedefleri (SKH) de aynı şekilde ortaya çıkmış olan bir strateji belgesidir. Yoksulluğu azaltmak, çevre duyarlılığını arttırmak, yönetişimi geliştirmek, toplumsal cinsiyet eşitsizliğiyle mücadele gibi temel amaçları barındıran bu dokümanlar, kalkınma yardımları alanında donör olarak faaliyet gösteren ülkelerin de uyması gereken evrensel ilkelerdir. Ancak; uluslararası kalkınma yardımlarının; politikasını, yöntemini ve ilkelerini belirleyen hakim kesim olan donörlerin, kendi çıkarlarıyla çeliştiğinde, bu ilkeleri görmezden gelmeleri ya da yeni kurallar ve ilkeler oluşturmaları mümkün olabilmektedir (Alesina ve Weder, 2002, s.1128). 
Dolayısıyla büyük veya küçük yaşanan bütün dönüşümlere rağmen özellikle geleneksel kalkınma yardımı anlayışını benimsemiş olan donörler açısından kalkınma yardımlarının temel amacı neredeyse hiç değişmemiştir. Donör ülkeler için kendi stratejik hedefleri ve/veya ulusal çıkarları söz konusuysa, bahse konu ilkeler tamamen göz ardı edilebilmektedir.

Diğer taraftan uluslararası kuruluşların öncülüğünde ortaya çıkan bazı argümanların, kalkınma yardımları üzerinde olumsuz bir etki meydana getirmesi de mümkün olabilmektedir. Bu bağlamda merkezi planlama hususu ön plana çıkmaktadır. Batı merkezci, hiyerarşik bakış açısının da bir sonucu olan bu husus, yardımların muhatabı olan faydalanıcılar ile donör arasında kopukluk oluşmasına sebep olmaktadır. Faydalanıcıların taleplerini ve önceliklerini gör(e)meyen donörlerin sundukları yardımlar, ciddi bir etkinlik problemiyle karşı karşıya kalmaktadırlar (Moyo, 2010, s.35-37).

Bu noktada, kalkınma yardımlarındaki etkisizliğin temel sebebinin, geleneksel kalkınma yardımları anlayışının ortaya çıkardığı, hiyerarşik bakış açısı olduğunu söylemek yanlış olmayacaktır. Bununla birlikte bu anlayışı benimseyen donör ülkelerin asıl amacının, yardımların etkinliği değil, kendi ulusal çıkarları olduğunu söylemek de mümkündür. Dolayısıyla bahse konu etkinlik meselesinin gündeme getirilmesi ve tartışılması bir çeşit retorikten ibarettir. 


\title{
EXTENDED ABSTRACT
}

\section{Traditional Development Assistance Understanding A Critical Overview}

\author{
Esat İpek - Erdal Tanas Karagöl \\ Ankara Yildırım Beyazıt University
}

The emergence of modern development aid is based on the Marshall Plan Aid implemented between 1948-1951. The plan was prepared for the re-development of war-torn European economies after the Second World War and went down in history as the first development aid of the modern world. A follow-up to the Marshall Plan, the Truman Doctrine has emerged with the aim of preventing the spread of communism and regaining the pre-war influence and powers in favor of the European states. Owing to the Truman Doctrine, many Western European countries have been included as donors except for the USA.

Western European countries, wanting to re-establish their ties with their former colonies, turned this into a continuous dependency relationship through development aid. This has led to the understanding of traditional development aid. Because of this model, whose theoretical foundations are based on Rostow's Five-Stage Development Model, European states once again gained hierarchical advantage over their former colonies (Gökgöz, 2015, p.3).

The fact that international organizations took their place on the world scene after the 1950s brought some changes to development aid area. Thanks to the countries that started to offer some of their aid through these institutions, international organizations have started to take place as donors in the area of development aid. Even though the traditional understanding of development aid has undergone a partial change at this point, it hasn't made any significant change on the perspective of donor countries concerning this area. As before, the national interests of donor countries remained the top priority in the provision of aid. (McMichael, 2012, p.61-63).

The most important reason for this conservatism is that the decisions taken by international organizations are shaped by donor countries that adopt the 
traditional understanding of development aid. These countries, which are dominant at the point of representation, have the ability to direct the decisions taken by international organizations in a way that their national interests are not harmed (Lancester, 2007, p. 38). In addition, it wouldn't be wrong to say that similarly, this situation continues in the area of development aid and all other international issues even today.

The modernist development paradigm that emerged after the 1950s further reinforced the existing hierarchy between donors and beneficiaries, who are the two main actors of the development aid area. This concept, formed within the understanding of Western European countries in particular, concretely distinguished the "West and others" distinction. This distinction, which has made Europe absolute right and a guide for development, shifted the concept of development from Europe to Latin America, Asia, Africa and the Middle East. The discourse that many countries in these regions are incapable of self-management and don't have the capacity to process their resources has become a legitimate reason for moving resources to the West. This situation re-established a dependency between the countries in these regions and Western Europe (Wallerstein, 2006).

The main purpose of development aid in theory is to support the development efforts of undeveloped and developing countries thanks to the resources, knowledge, experience and opportunities transferred from developed countries. However, due to the reasons explained above, this argument is nothing more than a rhetoric. Today, to what extent the theoretical intention of development aids, in which the national interests of the donor countries are accepted as the first priority, could be achieved is one of the most controversial topics in the area.

This study aims to analyze the contradiction historically and to present it concretely in the context of some selected country examples. While determining the selected countries as an example, it was paid attention that the countries to be the first countries having adopted the traditional development aid approach emerged after the 1950s and to be the countries that will provide evaluation regarding the structural and institutional transformations that can be shown as an example of how the historical process worked.

From the 1950s to the 1980s, the major infrastructure projects that Western European donor countries and the US have implemented within the scope of 
development aid for the purpose of power have started to transform into political and economic reforms after this date, such as the expansion of democracy and the adoption of a free market economy. One of the most important triggers of this transformation is the programs implemented by international organizations such as the World Bank and IMF (Dollar and Svensson, 2000, p.903).

The aforementioned programs implemented by international organizations have become the prerequisites for beneficiary countries to adopt and implement in order to benefit from development aid. The main purpose of these prerequisites is to make the beneficiary countries safe for investment in global capital. This situation, in which economic motives have become the main factor, completely pushes the priorities, needs and demands of the beneficiary countries into the background (McMichael, 2012, p.61-63).

This situation, which was the target of criticisms in the 1990s, caused these programs to focus on the problem of poverty. Strategy documents such as the Millennium Development Goals (MDGs), in which long-term goals have been set in many different subjects, have begun to emerge since the beginning of the 2000s. A follow-up to the MDG covering the years 2000-2015, Sustainable Development Goals (SDG) covering the years 2015-2030 is a strategy document that has emerged in the same way. These documents contain basic objectives such as reducing poverty, increasing environmental sensitivity, improving governance, and combating gender inequality state universal principles that countries operating as donors in development aid area should also comply. However, it is possible that donors, who determine the policy, method and principles of the international development aid, may ignore these principles or create new rules and principles when they find conflict with their own interests (Alesina and Weder, 2002, p.1128).

Therefore, the main purpose of development aid has almost never changed, especially for donors who have adopted the traditional understanding of development aid despite the large or small transformations. If the donor countries have their own strategic goals or national interests, these principles can be completely ignored.

On the other hand, it is possible that some arguments emerged under the leadership of international organizations may have a negative impact on development aids. In this context, central planning comes to the fore. This issue, which is also a result of the western-centered, hierarchical point of view, 
causes a disconnection between the drawee beneficiary and the donor. Donors who can't see the demands and priorities of the beneficiaries are faced with a serious effectiveness problem (Moyo, 2010, p.35-37).

At this point, it would not be wrong to say that the main reason for the ineffectiveness in development aid is the hierarchical perspective that traditional understanding of development aid brings. However, it is possible to say that the main purpose of donor countries that adopt this understanding is not their effectiveness but their own national interests. Therefore, it is nothing more than a rhetoric to bring effectiveness into question and discuss it.

\section{Kaynakça / References}

AidFlows (2020a) 08.02.2020 tarihinde https://www.aidflow.org/donör-view/thenetherlands-official-development-assistance adresinden erişilmiştir.

AidFlows (2020b) 28.02.2020 tarihinde https://www.aidflow.org/donörview/france-official-development-assistance adresinden erişilmiştir.

Alagöz, M. (2004) Sürdürülebilir kalkınmanın paradigması. Selçuk Üniversitesi Sosyal ve Ekonomik Araştırmalar Dergisi, 4(8), 1-23.

Alesina, A. ve Dollar, D. (2000) Who gives foreign aid to whom and why? Journal of Economic Growth, 5(1), 33-63.

Alesina, A. ve Weder, B. (2002) Do corrupt governments receive less foreign aid?, American Economic Review, 92(4) 1126-1137.

Arslan, Hacı Mahmut (2015), Kalkınma işbirliğinde donörlerin karşılaştırılması ve Türkiye için öneriler. Uzmanlık Tezi T. C. Kalkınma Bakanlığı Sosyal Sektörler ve Koordinasyon Genel Müdürlüğü, Ankara

Clay, E., Geddes, M. ve Natalı, L. (2009) Untying Aid: Is it working? An Evaluation of the Implementation of the Paris Declaration and of the DAC Recommendation of Untying ODA to the LDCs. Danish Institute for International Studies, Copenhagen.

Craig, D. ve Porter, D. (2003) Poverty reduction strategy papers: A new convergence. World Development, 31(1), 53-64.

Dollar, D., ve Svenson, J. (2000) What explains the success or failure of structural adjustment programmes? The Economic Journal, 110(466), 894-917.

Donor Tracker (2019). France donor profile. 28.12.2019 tarihinde https://donortracker.org/sites/default/files/donor pdfs/DonorTracker Profile France 2019 0.pdf adresinden erişilmiştir. 
Dreher, A., Nunnenkamp, P. ve Thiele, R. (2011) Are 'new' donors different? comparing the allocation of bilateral aid between Non-DAC and DAC donor countries. World Development, 39(11), 1950-1968.

Easterly, W. (2007) The white man's burden: Why the west's efforts to aid the rest have done so much ill and so little good?. New York, Penguin Books.

Easterly, W. ve Pfutze,T. (2008) Where does the money go? Best and worst practices in foreign aid. Journal of Economic Perspectives, 22(2), 29-52.

ECI (2013) About global partnership initiative, 05.01.2020 tarihinde http://effectivecooperation.org/related-initiatives-2/ adresinden erişilmiştir.

Ehrenfeld, D. (2004) Foreign aid effectiveness, political rights and bilateral distribution. The Journal of Humanitarian Assistance, https://sites.tufts.edu/jha/archives/75

France Ministry of Europe and Foreign Affairs (2019). Development - "The French and France's development assistance policy" barometer. 28.12.2019 tarihinde https://www.diplomatie.gouv.fr/en/french-foreign-policy/developmentassistance/news/events-2015/article/development-the-french-andfrance-s-development-assistance-policy-barometer-09 adresinden erişilmiştir.

Fuhrer, H. (1996) A history of the development assistance committee and the development co-operation directorate in dates, names and figures. OECD, OC/GD 67 (94), http://www.oecd.org/dac/1896816.pdf adresinden erişilmiştir.

Gökgöz, Ç., (2015). Kalkınma işbirliğinin yönetimi: Türkiye için model önerisi ve uygulama önerileri. Uzmanlık Tezi T. C. Kalkınma Bakanlığı Sosyal Sektörler ve Koordinasyon Genel Müdürlüğü, Ankara

Hoebink, P. (1999) The humanitarianisation of the foreign aid programme in Netherlands. European Journal of Development Research, 11(1), 176-202, London.

Kharas, H. J. ve Fengler, W. (2010) Delivering aid differently: Lessons from the Field. Washington D.C:Brooking Institution Press, 3-14.

Lancester C. (2007) Foreign aid: Diplomacy, development domestic politics. The Chicago:University of Chicago Press, 30-91.

Law Library of Congress (2011) Regulation of foreign aid in selected countries 2011/2012. Global Legal Research Center.

Mahmat, K., (2008) Küreselleşme sürecinde kalkınma yardımları: Orta Asya Cumhuriyetleri önneği. Yuksek Lisans Tezi, Ankara Universitesi, Ankara. 
Manning, R. (2006) Will 'emerging donors' change the face of international cooperation? Development Policy Review, 24(4), 371- 385.

Mawdsley, E. (2014) From recipients to donors: Emerging powers and the changing development landscape, London:Zed Books, 48-68.

McMichael, P. (2012) Development and social change: A Global perspective. Los Angeles:Sage, 61-63.

MFA of Netherlands (2020). 31.01.2020 tarihinde https://www.government.nl/documents/parliamentary-documents/2014/03/05/government-responseto-the-interministerial-policy-review-towards-a-new-definition-of-development-cooperation-considerations-on adresinden erişilmiştir.

Moyo, D. (2010) Dead aid: Why aid is not working and how there is a better way for Africa, Farrar. New York:Straus and Giroux, , 12-40.

OECD (2020) 08.02.2020 tarihinde https://data.oecd.org/oda/country-programmable-aid-cpa.htm\#indicator-chart adresinden erişilmiştir.

OECD. (2011) Survey on monitoring the Paris Declaration. 22.11.2019 tarihinde http://www.oecd.org/dac/effectiveness/2011surveyonmonitoringtheparisdeclaration.htm adresinden erişilmiştir.

Pettinger, T. (2017) Washington Consensus-Definition and Criticism. http://www.economicshelp.org/blog/7387/economics/washington-consensus-definition-and-criticism/adresinden erişilmiştir.

Sirolli, E. (1999) Ripples from the Zambezi: Passion, enterpreneurship and the rebirth of local economies. Gabriola Island, B.C:New Society Pulishers.

Six, C. (2009) The Rise of Post-colonial States as Donors: A Challenge to the Development Paradigm?. Third World Quarterly, 30(6), 1103- 1121.

Spitz, G., Muskens, R., ve van Ewijk, E. (2013) The Dutch and development cooperation: Ahead of the crowd or trailing behind?, NCDO, Amsterdam. http://www.ncdo.nl/sites/default/files/Report\%20Analysis\%20The\%20Dutch\%20and\%20Development\%20Cooperation\%20FINAL\%202013\%2003\%2004.pdf adresinden erişilmiştir.

UNDESA - United Nations Department of Economic and Social Affairs, (2015) LDC information: Graduation and transition process. 13.12.2019 tarihinde http://www.un.org/en/development/desa/policy/cdp/ldc/ldc graduated.shtm

USAID (2020a). Feed the future https://www.usaid.gov/feed-the-future/vision, 08.02 .2020

USAID (2020b) 08.02.2020 tarihinde https://www.usaid.gov/who-we-are/usaidhistory adresinden erişilmiştir. 
USAID (2020c) 08.02.2020 tarihinde https://www.usaid.gov adresinden erişilmiştir.

Wallerstein, I. (2006) European universalism: The rhetoric of power. New York:New Press.

Ziai, A. (2007) The meaning of development: A Critical Post-Culturalist Perspective. Journal Fur Entwicklungspolitik, 23(2), 64-65.

\section{Kaynakça Bilgisi / Citation Information}

İpek, E. ve Karagöl, E. T. (2020). Geleneksel kalkınma yardımı anlayışına eleştirel bir bakış OPUS-Uluslararası Toplum Araştırmaları Dergisi, 15(10. Yıl Özel Say1s1), 5410-5437. DOI: 10.26466/opus.690706 